\title{
3D Numerical Analysis of the Effects of an Advancing Tunnel on an Existing Loaded Pile Group
}

\author{
Mukhtiar Ali Soomro \\ Department of Civil \\ Engineering, Quaid-e-Awam \\ University of Engineering, \\ Science \& Technology \\ Nawabshah, Pakistan \\ eng.soomro@gmail.com
}

\author{
Daddan Khan Bangwar \\ Department of Civil \\ Engineering, Quaid-e-Awam \\ University of Engineering, \\ Science \& Technology \\ Nawabshah, Pakistan \\ skb_khan2000@yahoo.com
}

\author{
Mohsin Ali Soomro \\ Department of Civil \\ Engineering, Quaid-e-Awam \\ University of Engineering, \\ Science \& Technology \\ Nawabshah, Pakistan \\ drmohsin@quest.edu.pk
}

\author{
Manthar Ali Keerio \\ Department of Civil \\ Engineering, Quaid-e-Awam \\ University of Engineering, \\ Science \& Technology \\ Larkana, Pakistan \\ Mantharali99@quest.edu.pk
}

\begin{abstract}
Tunnels are often preferred for underground transportation in densely populated areas. In these areas, it is almost inevitable for tunnels to run close to some existing pile foundations. Since tunnelling activities induce stress relief and soil movement in the ground, existing piles may suffer from additional axial and lateral forces, bending moments, settlements and lateral deflections. Most of the previous researches on the responses of pile foundations due to tunnel construction were carried out under the plane strain condition. In this paper, a three-dimensional, elasto-plastic and coupled-consolidation finite element parametric study has been carried out to investigate the effects of a $6 \mathrm{~m}$ open-face advancing tunnel on a two by two pile group in saturated stiff clay. The influence of different cover-todiameter $(C / D)$ tunnel ratios (namely $2.0,2.5 \& 3.0$ ) was studied. The objectives of this study are to determine the changes in axial load distribution, changes in shaft resistance along the shaft of pile group and settlement of pile cap due to an advancing openface tunnel.
\end{abstract}

Keywords-finite element analysis; open face tunnelling; settlement of pile cap

\section{INTRODUCTION}

A piled foundation transfers the load of the structure into the ground, generating stresses in the surrounding soil. In contrast, tunnel excavation induces stress relief to the surrounding soil and results in ground movements around the tunnel, which propagate through the soil to the ground surface. Nowadays, tunnelling is a very popular technique to facilitate congested urban traffic systems in big cities like London, Hong Kong and Singapore. Since tunnel construction inevitably induces soil movement and stress changes in the ground, it may cause additional settlement and tilting to nearby existing piled foundations. Tunnelling remains a big challenge for geotechnical engineers, particularly when a tunnel is to be excavated in soft ground. To understand the pile-soil-tunnel interaction mechanism, many researchers have conducted field monitoring studies and centrifuge model tests [1-9]. Moreover, this problem has also been studied by the proposing of analytical solutions and numerical modelling [10-19]. All authors in [10-19] concluded that tunneling adjacent to existing pile foundations caused pile settlement, additional axial load on piles and induced bending moments along piles, which is unfavourable for piled foundations. The magnitudes of which likely depended on the relative locations of tunnels and piles.

Authors in [20] described the effects of a $7.5 \mathrm{~m}$ tunnel excavated in stiff London clay on a bored piled foundation. The clear spacing between the springline of the tunnel and the nearest $1.2 \mathrm{~m}$ diameter pile was only $1 \mathrm{~m}$. The measured horizontal pile and ground movements were similar. Maximum horizontal displacement of $10 \mathrm{~mm}$ of the nearest pile to the tunnel was reported. Authors in [21] reported the measured settlement of a building due to the excavation of a $7.9 \mathrm{~m}$ diameter tunnel in Hong Kong. The building was supported by $2 \mathrm{~m}$ diameter bored piles varying in length from $41 \mathrm{~m}$ to $64 \mathrm{~m}$. The tunnel depth was above the level of the pile toe. Maximum building settlement due to tunnel construction was recorded to be $12 \mathrm{~mm}$. Authors in [22] reported measured results of the effects of $6.5 \mathrm{~m}$ diameter shield tunneling on the adjacent piled foundations of bridge piers in Singapore. The piers were supported by $2 \times 2$ pile group of $1.2 \mathrm{~m}$ diameter and $62 \mathrm{~m}$ long piles. The piles were embedded in completely weathered material (residual soil) with SPT values varying from 15 to 100. The nearest tunnel-pile foundation distance was $1.6 \mathrm{~m}$. Tunnel depth was located at about the mid pile depth (i.e. 21 $\mathrm{m})$. The maximum volume loss due to the tunnel excavation was reported as high as $1.5 \%$. The monitoring results showed that the piles were subjected to large dragload, and the maximum induced bending moment in the piles was at the tunnel springline due to the tunnel advancement. Authors in [23] carried out a 3D elasto-palstic analysis to study the effects of a tunnel on a single pile and a $2 \times 2$ pile group pile group at different cover-to-tunnel-diameter (C/D) ratios. Computed results showed that there was significant reduction of the induced axial force and bending moment on the pile furthest away from the tunnel (i.e., the rear pile) due to the group effect. 
However, the settlement, tilting of the pile group and the load transfer mechanism between piles was not reported [23].

In previous studies, researchers were mostly interested in the tunnelling-induced axial forces and bending moments in piles due to tunnel excavation. The load transfer within the piles of a group and the induced tilting due to the tunnel advancement has not been reported. Besides this, the location of a tunnel relative to a pile foundation has not been studied systematically. With the prime objective of investigating the tunnel location effects relative to the piled foundation, 3D parametric coupled-consolidation finite element analyses were carried out at different cover-to-tunnel-diameter ratios $(\mathrm{C} / \mathrm{D}=$ 1.5, 2.5 and 3.5). The effects of an advancing, open face, $6 \mathrm{~m}$ diameter tunnel on a $2 \times 2$ pile group in stiff saturated clay were investigated. Settlement, pile group tilting and load transfer among piles at various tunneling stages were studied and discussed.

\section{3D COUPLED-CONSOLIDATION ANALYSES}

A hypothetical tunnel excavation in a stiff, nonhomogeneous and over consolidated saturated clay is modeled. Figure 1 shows tunnel geometry and pile group size and location relative to the tunnel. Tunnel diameter (D) is taken as $6 \mathrm{~m}$ with different cover depths (C) of $12 \mathrm{~m}, 15 \mathrm{~m}$ and $18 \mathrm{~m}$. A $(2 \times 2)$ pile group with $2.5 \mathrm{~m}$ center to center distance, $19 \mathrm{~m}$ length ( $1 \mathrm{~m}$ above ground surface) and each pile, with $0.8 \mathrm{~m}$ diameter, is located at a distance of $5.5 \mathrm{~m}$ from tunnel center line. For the ease of descriptions and discussion, P1 and P2 are referred as front and rear piles, respectively (see Figure 1b). The purpose of this numerical study is to investigate the effect of tunneling on the nearby pile group at different $\mathrm{C} / \mathrm{D}$ ratios, while keeping the pile group length unchanged. The finite element program, ABAQUS, was used to carry out these numerical analyses.

\section{A. Finite Element Mesh and Boundary Conditions}

Figure 2 shows a three-dimensional finite element mesh (soil, pile group and pile cap), adopted for all the numerical runs. Taking advantage of symmetry, only the half of the domain is simulated at $\mathrm{x}=0$. The finite element mesh is $60 \mathrm{~m}$ long, $60 \mathrm{~m}$ wide and $36 \mathrm{~m}$ high. This mesh consists of 12,276 elements and 15,331 nodes. The eight-noded brick elements, four-noded shell elements and two-noded beam elements are used to model the soil, lining and pile cap and pile group, respectively. A monitoring section is selected at pile group center line for reference. Roller supports and pin supports are applied on vertical sides and mesh base respectively. Therefore, the movement to normal direction of vertical sides of mesh and movement in all directions of mesh base are restrained. The water table is assumed to be located at ground surface. At the first step pore water pressure distribution profile is assumed to be hydrostatic. Free drainage is allowed at the top of the mesh. Tunnel lining is assumed to be impervious.

\section{B. Constitutive Models and Model Parameters}

An elasto-plastic soil model using Drucker-Prager failure criterion with non-associated flow rule is used to model the behaviour of stiff clay for these numerical analyses. The strength parameters effective cohesion (c'), effective angle of friction $\left(\phi^{\prime}\right)$ and angle of dilation $(\psi)$ for stiff clay are assumed as $5 \mathrm{kPa}, 20^{\circ}$ and $11^{0}$ respectively [12]. Stiffness parameters for stiff clay are assumed as anisotropic and increase linearly with depth [1]. All the soil parameters used for the numerical analyses are summarized in Table 1. The concrete piles, cap and tunnel lining are assumed to be linear elastic with Young's modulus of $35 \mathrm{GPa}$ and Poisson's ratio as 0.25. Lining thickness and pile cap are taken as $0.25 \mathrm{~m}$ and $1 \mathrm{~m}$ respectively. The unit weight of concrete is assumed $24 \mathrm{kN} / \mathrm{m}^{3}$. Piles are assumed to be rigidly connected with cap.

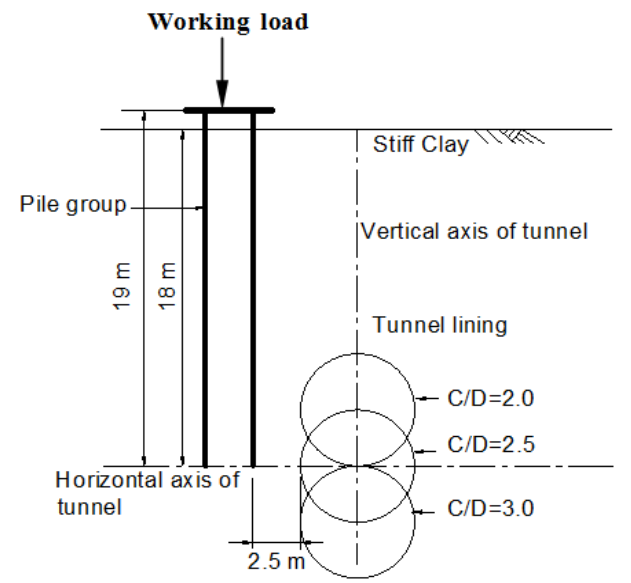

(a) Sectional view

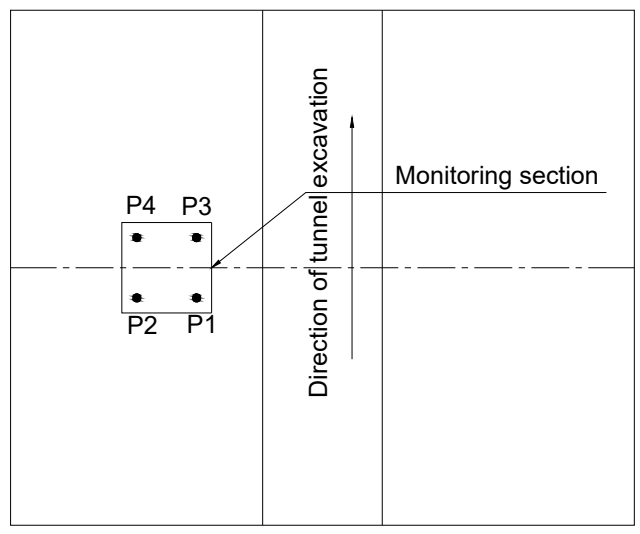

(b) Plan view

Fig. 1. Geometry of problem studied

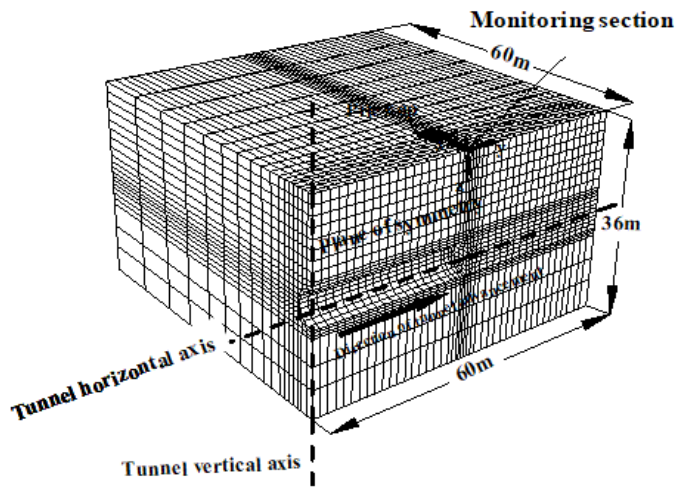

Fig. 2. Three-dimensional finite element mesh 
TABLE I. SOIL PARAMETERS USED IN FINITE ELEMENT ANALYSES.

\begin{tabular}{|c|c|}
\hline \multicolumn{2}{|c|}{ Soil Parameter } \\
\hline Dry density $\left(\gamma_{\mathrm{d}}\right)$ & $1500 \mathrm{~kg} / \mathrm{m} 3$ \\
\hline Void ratio $(\mathrm{i})$ & 1.0 \\
\hline Vertical effective Young's modulus $\left(\mathrm{E}_{\mathrm{v}}^{\prime}\right)$ & $7500+3900 \cdot \mathrm{Z} \mathrm{kPa}$ \\
\hline Horizontal effective Young's modulus $\left(\mathrm{E}_{\mathrm{h}}^{\prime}\right)$ & $12000+6240 \cdot \mathrm{Z} \mathrm{kPa}$ \\
\hline Shear modulus in vertical plane $\left(\mathrm{G}_{\mathrm{vh}}\right)$ & $0.44 \mathrm{E}^{\prime} \mathrm{v} \mathrm{kPa}$ \\
\hline $\mathrm{n}=\mathrm{E}_{\mathrm{h}}^{\prime} / \mathrm{E}_{\mathrm{v}}^{\prime}$ & 1.6 \\
\hline Poisson's ratio $(v)$ & 0.125 \\
\hline Coefficient of permeability $(\mathrm{k})$ & $1 \times 10-9 \mathrm{~m} / \mathrm{s}$ \\
\hline Effective cohesion $\left(\mathrm{c}^{\prime}\right)$ & $5 \mathrm{kPa}$ \\
\hline Effective angle of friction $\left(\phi^{\prime}\right)$ & $22^{0}$ \\
\hline Angle of dilation $(\psi)$ & $11^{0}$ \\
\hline Coefficient of lateral earth pressure at rest $\left(\mathrm{K}_{0}\right)$ & 1.0 \\
\hline
\end{tabular}

\section{Numerical Modeling Procedure}

Two separate numerical runs were carried out on two different finite element meshes. The first numerical run was conducted to determine the ultimate axial load carrying capacity of pile group and the second numerical run was conducted to determine the effects on pile group. The numerical modeling procedure steps are summarized as follows:

1. Establish the initial stress condition using $\mathrm{K}_{0}=1.0$.

2. Determine the axial load carrying capacity of wished-inplace pile group from numerical load test by conducting first numerical run.

3. Then create another mesh with same initial stress condition as in Step 1. Carry out second numerical run after applying working load, computed from first numerical run, on pile group with $\mathrm{FOS}=3$ at initial stress condition.

4. Allow the excess pore pressure to dissipate, developed in response of working load on pile group.

5. Then start to excavate tunnel with $3 \mathrm{~m}(\mathrm{D} / 2)$ unsupported length.

6. Apply the $250 \mathrm{~mm}$ thick lining to exposed surface of tunnel.

7. Advance the tunnel excavation, repeating the same procedure until the tunnel is completed.

An open face tunnel sequential excavation was modeled in this study. Tunnel excavation was simulated by deactivating the elements located in tunnel zone and tunnel lining was simulated by activating elements of lining.

\section{Determination of Pile Group Axial Load Capacity}

Prior to tunnel excavation, it is desirable to determine pile group axial load carrying capacity. For this purpose, a numerical pile load test was carried out. In pile test, load was increased from 0 to $24,000 \mathrm{kN}$ on the pile cap middle for over a period of 24 hours. Figure 3 shows the load settlement curve obtained from the pile load test. The ultimate axial load capacity was determined based on new displacement-based failure criterion proposed in [10]. The failure criterion is expressed as follows:

$$
\delta_{p h \text { max }} \cong 0.045 d_{p}+\frac{1}{2} \frac{P_{h} L_{p}}{A_{p} E_{p}}
$$

where $P_{h}=$ pile head load, $L_{p}=$ pile length, $E_{p}=$ pile shaft elastic modulus, $\mathrm{A}_{\mathrm{p}}=$ Cross sectional area of pile and $\mathrm{d}_{\mathrm{p}}=$ pile diameter. As shown in Figure 3, the ultimate load capacity of the simulated pile group was determined to be $21,210 \mathrm{kN}$. With a factor of safety 3.0, a working load of 7,070 kN was applied on the mid of pile cap. An initial pile cap settlement of $6.5 \mathrm{~mm}$ $(0.8 \% \mathrm{dp})$ was calculated due to applied working load. The excess pore pressure, generated due to working load prior to tunnel excavation, was allowed to fully dissipate.

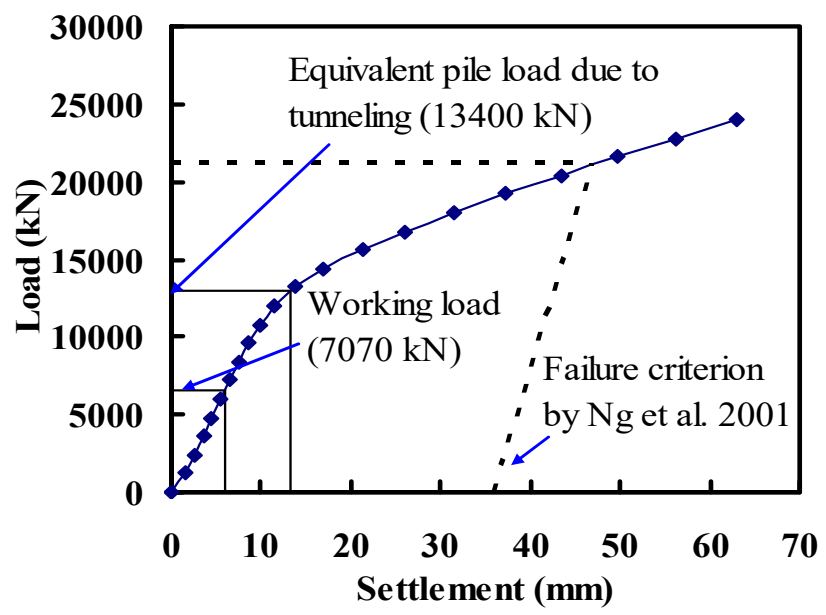

Fig. 3. Load settlement curve of simulated pile group load test

\section{COMPUTED RESULTS}

In this section, computed results are presented. From the computed data, it was observed that the most critical moment is when tunnel face aligns with the pile group center line (monitoring section). However, there are not any significant changes in surface settlement as tunnel face passes beyond the $y / D \geq 3$ from the monitoring section. Therefore, it can be assumed that monitoring section attains the plane strain condition.

\section{A. Transverse Surface Settlement Trough}

Figure 4 shows the normalized immediate surface settlements $(\mathrm{S})$, when tunnel face reached monitoring section $(y / D=0)$ and at the plane strain condition, when tunnel face passed beyond monitoring section at a distance of $y / D \geq 3$, for all three cases. Although the surface settlements were initially induced due to load applied on the pile group, only tunnellinginduced settlements are considered here. It can be seen that immediate settlement is less than settlement at plane strain condition. This occurs because of the dissipation of excessive pore water pressure, after the tunnel face has passed through monitoring section. The Gaussian distribution curves [11] are fitted on the basis of $S_{\max }$ and i (distance from tunnel center line to the curve inflexion point) at plane strain condition, computed from each numerical analysis. The calculated values of $i$, at 
plane strain condition are $9.9 \mathrm{~m}, 10.8 \mathrm{~m}$ and $11.7 \mathrm{~m}$ from tunnel center line for $\mathrm{C} / \mathrm{D}=2.0,2.5$ and 3.0, respectively. The computed maximum surface settlements at tunnel center line are $10.3 \mathrm{~mm}, 10 \mathrm{~mm}$ and $9 \mathrm{~mm}$ for $\mathrm{C} / \mathrm{D}=2.0,2.5$ and 3.0 respectively. Based on $\mathrm{S}_{\max }$ and i, it can be observed that with the increase of $\mathrm{C} / \mathrm{D}$ ratio, maximum settlement decrease and settlement trough become wider. The volume loss associated due to tunnel excavation calculated on the basis of area of settlement trough is about $0.9 \%$ for each case.

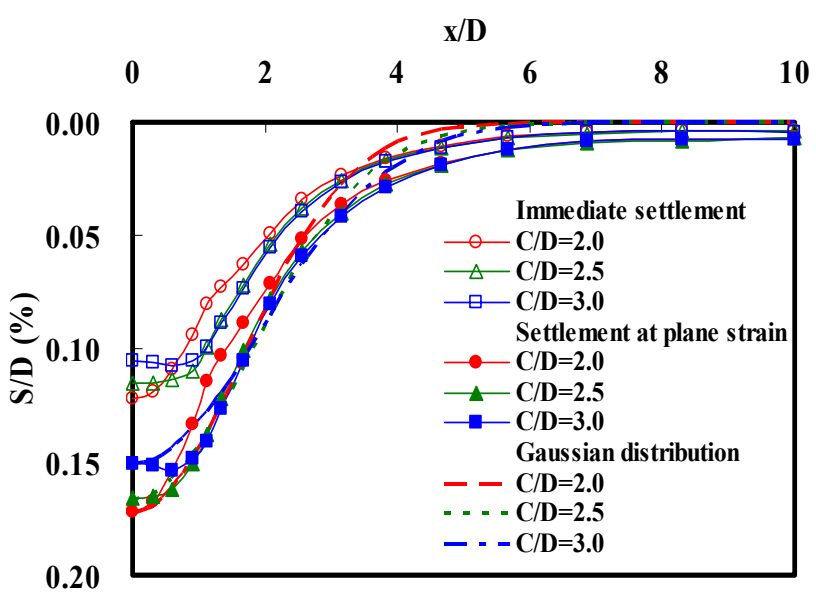

Fig. 4. Transverse settlement at monitoring section due to tunnelling

\section{B. Pile Group Settlement Due to Tunnel Advancement}

Figure 5 shows the incremental settlement of pile group due to tunnelling for $\mathrm{C} / \mathrm{D}=2.0,2.5$ and 3.0. It can be observed that as tunnel advances to monitoring section, excessive settlement occurs in the pile group. In the case of $\mathrm{C} / \mathrm{D}=2.0$, the pile group settlement due to tunneling is less than in the other cases. Settlement profiles for the cases $C / D=2.5$ and $C / D=3.0$ are similar because the pile group base is subjected to stress release due to tunneling in both cases. The pile group settlements due to tunneling advancement are $5.6 \mathrm{~mm}$ for $\mathrm{C} / \mathrm{D}=2.0$ and $7.5 \mathrm{~mm}$ for both $\mathrm{C} / \mathrm{D}=2.5$ and $\mathrm{C} / \mathrm{D}=3.0$ at plane strain conditions (i.e. $\mathrm{y} / \mathrm{D} \geq 3$ ). This implies that total pile group settlement due to tunneling is $12 \mathrm{~mm}(1.5 \% \mathrm{dp})$ for $\mathrm{C} / \mathrm{D}=2.0$ and $14 \mathrm{~mm}$ $(1.75 \% \mathrm{dp})$ for $C / D=2.5$ and $C / D=3.0$. Since there is not much difference in total pile group settlement for all three cases, therefore from load settlement curve (Figure 3), the load corresponding to $14 \mathrm{~mm}$ settlement is $13,400 \mathrm{kN}$. It can be considered that the pile group is subjected to an equivalent load of $13,400 \mathrm{kN}$ after tunnel passes beyond monitoring section, which reduces the factor of safety from 3.0 to 1.6 in each case.

\section{Changes in Unit Shaft Friction Along the Length of Pile P1 and Pile P2 Due to Tunnelling.}

Figure 6 shows the changes in the unit shaft friction along the shafts of both $\mathrm{P} 1$ and $\mathrm{P} 2$, when tunnel face is at monitoring section (i.e. $y / D=0$ ). The unit shaft friction reduces significantly in $\mathrm{P} 1$ at the upper part of the shaft (i.e. $0 \leq \mathrm{z} / \mathrm{D} \leq 2.5$ ), when tunnel is located at $C / D=2.0$. It indicates the reduction in shaft resistance because of the stress release around P1 due to tunneling. The maximum reduction of $35 \mathrm{kPa}$ in unit shaft friction of $\mathrm{P} 1$ is observed at the tunnel crown (i.e. $\mathrm{z} / \mathrm{D}=2.0$ ). However, the unit shaft friction increases along the lower part of $\mathrm{P} 1$ below tunnel horizontal axis $(\mathrm{z} / \mathrm{D} \geq 2.5)$. As a result, base load of P1 is increased. Unit shaft friction also reduces along the upper part of shaft of $\mathrm{P} 2$ (i.e. $\mathrm{z} / \mathrm{D} \leq 2.25$ ). The increment in unit shaft friction at the lower part of shaft of P2 shows that base load is mobilized. It is clear that most of the load has transferred to the pile group base in case of $C / D=2.0$. When the tunnel is located at $C / D=2.5$, unit shaft friction increases along the upper part of the shaft (i.e. $\mathrm{z} / \mathrm{D} \leq 1.4$ ) of P1. However, the unit shaft friction near the base of P1 is reduced. It implies that no significant base load is mobilized which is discussed below. However, the negligible reduction in unit shaft friction is observed along the shaft of $\mathrm{P} 2$ except for the lower part of the shaft. It suggests that both shaft friction and base load of P2, support the additional load transferred from P1. It can be observed that unit shaft friction increases along the upper part of the shaft $(\mathrm{z} / \mathrm{D} \leq 2.25)$ of $\mathrm{P} 1$ in the case of $\mathrm{C} / \mathrm{D}=3.0$. However, unit shaft friction reduces significantly at the lower part of P1 (i.e. $\mathrm{z} / \mathrm{D}>2.25$ ). This shows that the base load of $\mathrm{P} 1$ reduces significantly. The maximum reduction of $44 \mathrm{kPa}$ in unit shaft friction occurs at tunnel crown $(\mathrm{z} / \mathrm{D}=3.0)$. However, unit shaft friction along the upper part of the shaft of P2 $(0 \leq \mathrm{z} / \mathrm{D} \leq 2.5)$ almost remained unchanged. The shaft resistance increases at the lower part $(\mathrm{z} / \mathrm{D} \geq 2.5)$ of $\mathrm{P} 2$. It suggests that the load is shared by both shaft resistances and the pile base. Most of the load in P1 is supported by shaft resistance after tunnel face passes through monitoring section in the case of $C / D=3.0$.

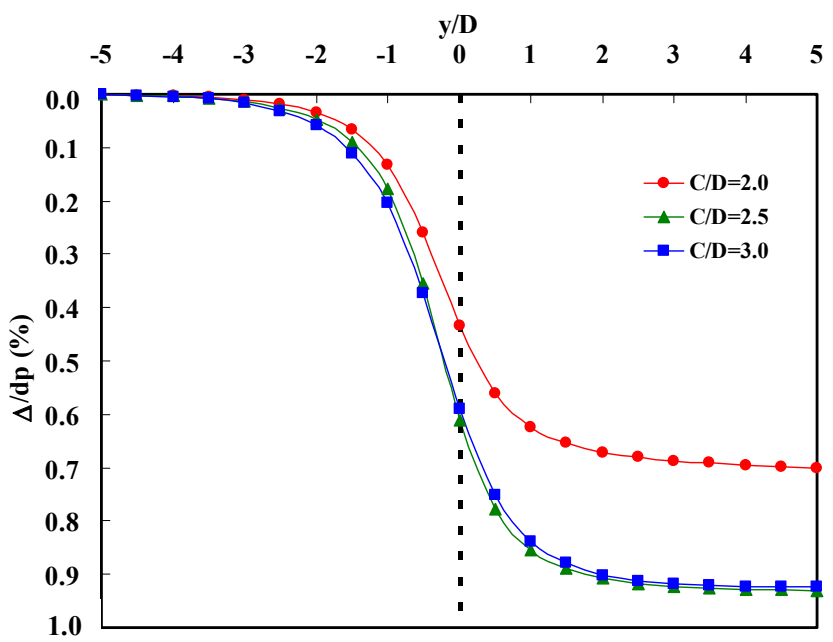

Fig. 5. Pile cap settlement due to tunnel advancement

Unit shaft friction is decreased significantly in P1 and P2 above the tunnel crown, when tunnel is located at $\mathrm{C} / \mathrm{D}=2.0$. As a result, base load of P1 is increased and pile head load is significantly decreased. Pile head load and base load of P2 increased substantially. It is clear that some part of the load is transferred to the base of $\mathrm{P} 1$ and some part of the load is transferred to $\mathrm{P} 2$. The head load of $\mathrm{P} 1$ reduced by $8 \%$, whereas the head load of P2 increased by 7\%. The base load of both piles $\mathrm{P} 1$ and $\mathrm{P} 2$ increases by $60 \%$ and $32 \%$, respectively. In the case of $C / D=2.5$, tunnel horizontal axis is at the pile group base (i.e. $z / D=3.0$ ). Therefore, almost negligible change is observed 
in the base of both piles. Due to load transfer mechanism in pile group, the load transfers from $\mathrm{P} 1$ to $\mathrm{P} 2$. The reduction in pile head load is $10 \%$ and pile head load of P2 increased $10 \%$ of total load on each pile. The base load of P2 is mobilized to take additional vertical load, transferred from P1, to maintain vertical equilibrium. The base load of $\mathrm{P} 1$ and $\mathrm{P} 2$ increased $13 \%$ and $30 \%$, respectively. When the tunnel is located at $\mathrm{C} / \mathrm{D}=3.0$, almost no change of shaft friction is observed along the shaft of P1. However, base load of P1 reduces significantly. It is because the tunnel crown is located at the pile base (i.e. $\mathrm{z} / \mathrm{D}=2.5$ ). To establish vertical equilibrium, the load transfers from $\mathrm{P} 1$ to $\mathrm{P} 2$. As a result of this, base load of P2 is mobilized to carry the additional load transferred from P1. The head and base load of $\mathrm{P} 1$ reduce $7 \%$ and $35 \%$ respectively. The head and base load of pile P2 increase $7 \%$ and $11 \%$, respectively.

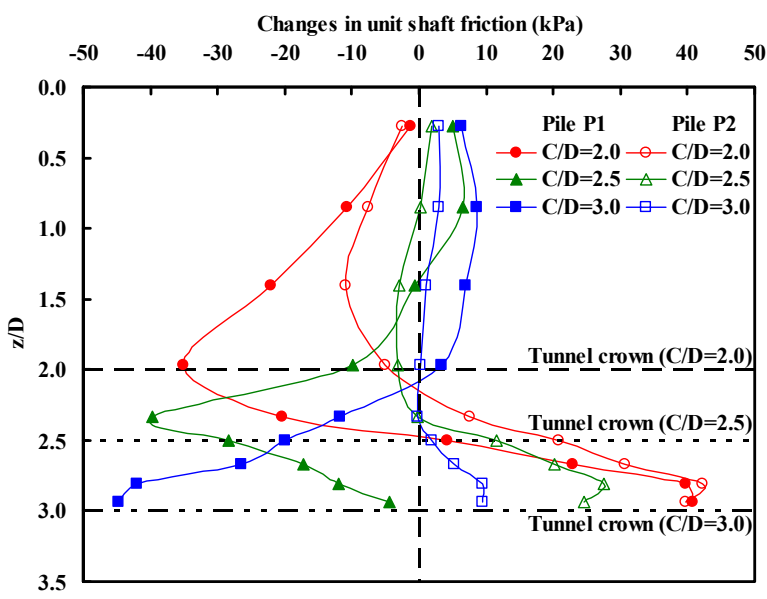

Fig. 6. Changes in unit shaft friction due to tunnelling

Axial load (kN)

$\begin{array}{llllllllllll}0 & 200 & 400 & 600 & 800 & 1000 & 1200 & 1400 & 1600 & 1800 & 2000 & 2200\end{array}$

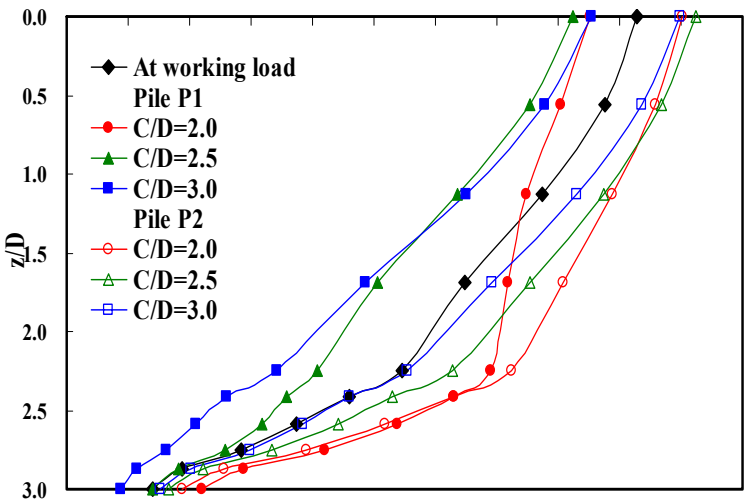

Fig. 7. Axial load changes in P1 and P2 due to tunnelling

\section{CONCLUSIONS}

Computed results make clear that surface settlement troughs at monitoring sections follow Gaussian distribution curve very well for all three cases. When the tunnel is excavated at $\mathrm{C} / \mathrm{D}=2.0$, it causes the reduction of shaft resistance in both the front $(\mathrm{P} 1)$ and rear $(\mathrm{P} 2)$ piles and load transfers from front pile to rear pile. This leads to an increase in base load by $60 \%$ and $32 \%$ in the front and rear piles, respectively. When tunnel is constructed at $C / D=2.5$, the shaft resistance and base load of front pile reduces significantly. Consequently, the load transfers from the front (P1) to the rear (P2) pile. The base load as well as shaft resistance of the rear pile is mobilized to support additional vertical load, transferred from the front pile to maintain equilibrium. Each base load of front and rear piles increases by $13 \%$ and $30 \%$, respectively. When tunnel is excavated at $\mathrm{C} / \mathrm{D}=3.0$ (i.e. the tunnel crown is located at pile base), the excavation causes the reduction of $35 \%$ in the base load of front pile (P1) and leads to load transfer from the front to the rear piles. This results in an increase of base load of rear pile (P2) by $11 \%$. The maximum reduction of $35 \mathrm{kPa}, 40 \mathrm{kPa}$ and $44 \mathrm{kPa}$ in unit shaft friction is observed near tunnel crown in case of $\mathrm{C} / \mathrm{D}=2.0,2.5$ and 3.0, respectively. Due to the additional settlement of pile group resulting from tunnelling, it can be deduced that the pile group is subjected to an additional equivalent load of $13,400 \mathrm{kN}$. This means that the factor of safety for pile group is reduced from 3.0 to 1.6 in each case.

\section{REFERENCES}

[1] A. Bezuijen, J. S. van der Schrier, "The influence of a bored tunnel on pile foundations", Centrifuge'94, pp. 681-686, 1994

[2] T. Boonyarak, K. Phisitkul, C. W. W. Ng, W. Teparaksa, Z. Z. Aye, "Observed ground and pile group responses due to tunneling in Bangkok stiff clay", Canadian Geotechnical Journal, Vol. 51, No.5, pp. 479-495, 2014

[3] S. W. Jacobsz, J. R. Standing, R. J. Mair, T. Hahiwara, T. Suiyama, "Centrifuge modeling of tunneling near driven piles", Soil and Foundations, Vol. 44, No. 1, pp. 49-56, 2004

[4] C. J. Lee, K. H. Chiang, "Responses of single piles to tunneling-induced soil movements in sandy ground", Canadian Geotechnical Journal, Vol. 44, No.10, pp. 1224-1241, 2007

[5] A. M. Marshall, R. J. Mair, "Tunneling beneath driven or jacked endbearing piles in sand", Canadian Geotechnical Journal, Vol. 48, No.12, pp.1757-1771, 2011

[6] C. W. W. Ng, H. Lu, "Effects of construction sequence of twin tunneling at different depth on a single pile", Canadian Geotechnical Journal, Vol. 51, pp. 173-183, 2013

[7] C. W. W. Ng, H. Lu, S. Y. Peng, "Three-dimensional centrifuge modeling of effects of twin tunneling on as existing pile", Tunneling and Underground Space Technology, Vol. 35, pp. 189-199, 2013

[8] C. W. W. Ng, M. A. Soomro, Y. Hong, "Three-dimensional centrifuge modelling of pile group responses to side-by-side twin tunnelling", Tunnelling and Underground Space Technology, Vol. 43, pp.350-361, 2014

[9] C. W. W. Ng, Y. Hong, M. A. Soomro, "Effects of piggyback twin tunnelling on a pile group: 3D centrifuge tests and numerical modelling", Geotechnique , Vol. 65, No. 1, pp. 38-51, 2015

[10] L. T. Chen, H. G. Poulos, N. Loganathan, "Pile responses caused by tunneling”, Journal of Geotechnical and Geoenvironmental Engineering, Vol. 125, No. 3, pp. 207-215, 1999

[11] C. Y. Cheng, G. R. Dasari, Y. K. Chow, C. F. Leung, "Finite element analysis of tunnel-soil-pile interaction using displacement controlled model", Tunneling and Underground Space Technology, Vol. 22, pp. 450-466, 2007

[12] M. Huang, C. Zhang, Z. Li, "A simplified analysis method for the influence of tunneling on grouped piles", Tunneling and Underground Space Technology, Vol. 24, pp. 410-422, 2009 
[13] Y. Hong, M. A. Soomro, C. W. W. Ng, "Settlement and load transfer mechanism of pile group due to side-by-side twin tunnelling", Computers and Geotechnics, Vol. 64, pp.105-119, 2015

[14] C. J. Lee, "Numerical analysis of the interface shear transfer mechanism of a single pile to tunnelling in weathered residual soil", Computers and Geotechnics, Vol. 42, pp.193-203, 2012

[15] C. J. Lee, "Three-dimensional numerical analyses of the response of a single pile and pile groups to tunnelling in weak weathered rock", Tunnelling and Underground Space Technology, Vol. 32, pp.132-142, 2012

[16] C. J. Lee, "Numerical analysis of pile response to open face tunnelling in stiff clay", Computers and Geotechnics, Vol. 42, pp. 116-127, 2013

[17] A. M. Marshall, "Tunnel-pile interaction analysis using cavity expansion methods", Journal of Geotechnical and Geoenvironmental Engineering, Vol. 138, No. 10, pp.1237-1246, 2012

[18] H. Mroueh, I. Shahrour, "Three-dimensional finite element analysis of the interaction between tunnelling and pile foundations", International Journal for Numerical and Analytical Methods in Geomechanics, Vol. 26, No. 3, pp. 217-230, 2002

[19] G. T. K. Lee, C. W. W. Ng, "The effects of advancing open face tunneling on an existing loaded pile", Journal of Geotechnical and Geoenvironmental Engineering, Vol. 131, No. 2, pp.193-201, 2005

[20] R. J. Mair, R. N. Taylor, "Bored tunneling in the urban environment", 14th International Conference on Soil Mechanics and Foundation Engineering, Balkema, Vol.4, pp.2353-2385, 1997

[21] R. A, Forth, C. B. B, Thorley, "Hong Kong Island line predictions and performance", International Symposium on Geotechnical Aspects of Underground Construction in Ground, Balkema, pp. 677-682, 1996

[22] D. R. Coutts, J. Wang, "Monitoring of reinforced concrete piles under horizontal and vertical loads", International Conference on Tunnels and Underground Structures, pp. 541-546, 2000

[23] K. W. D. Tang, "Numerical studies of multiple NATM tunnel interaction in soft ground", MSc Thsis, The Hong Kong University. of Science and Technology, Hong Kong, 2001

[24] J. B. Burland, J. C. Kalra, "Queen Elizabeth II Conference Center: Geotechnical aspects", Proceedings of the Institution of Civil Engineers, Vol. 80, No. 6, pp. 1479-1503, 1986

[25] C. W. W. Ng, T. L. Y. Yau, J. H. M. Li, W. H. Tang, "New failure load criterion for large diameter bored piles in weathered geomaterials", Journal of Geotechnical and Geoenvironmental Engineering, Vol. 127, No. 6, pp. 488-498, 2001

[26] R. B. Peck, "Deep excavations and tunnelling in soft ground", 7th International Conferenve SMFE, State of the Art, Vol. 3, pp. 225-290, 1969 